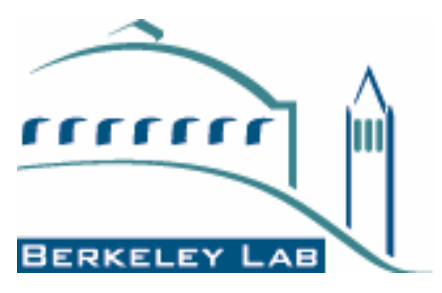

\title{
LESSONS LEARNED AND BEST PRACTICES PROGRAM MANUAL
}

\author{
LBNL PUB-5519 (4), Rev. 0
}

Effective Date:

\author{
Ernest Orlando Lawrence \\ Berkeley National Laboratory
}




\section{RECORD OF REVISION}

\begin{tabular}{||c|c|c||}
\hline $\begin{array}{c}\text { Revision } \\
\text { Number }\end{array}$ & Date Approved & Description of Revision \\
\hline & & \\
\hline & & \\
\hline & & \\
\hline
\end{tabular}




\section{TABLE OF CONTENTS}

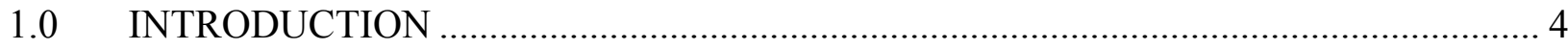

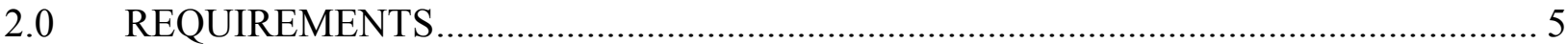

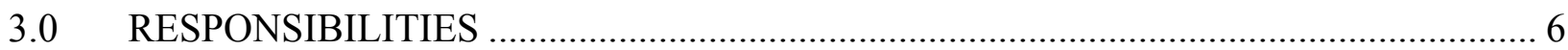

4.0 LESSONS LEARNED DEVELOPMENT …........................................................ 7

5.0 BEST PRACTICES DEVELOPMENT ............................................................ 8

6.0 LESSONS LEARNED AND BEST PRACTICES EFFECTIVENESS......................... 9 


\subsection{INTRODUCTION}

This document provides requirements and guidelines for conducting a Lessons Learned and Best Practices Program within Lawrence Berkeley National Laboratory (LBNL) to ensure ongoing improvement of safety and reliability, prevent the recurrence of significant adverse events/trends, and determine implementation strategies that will help LBNL successfully meet the missions and goals set forth by the Department of Energy (DOE).

Based on LBNL's and other DOE facilities' operating experience, Lessons Learned and Best Practices Briefings will be developed and distributed to applicable personnel and organizations.

This procedure applies to personnel who initiate Lessons Learned/Best Practices Briefings or who are assigned to perform activities using this document.

Events, issues, or incidents that may have a significant impact on safety and operations and/or could lead to potential fines for regulatory infractions will be identified and addressed in Lessons Learned Briefings. Lessons Learned from LBNL may be applicable to other national laboratories across the Department of Energy (DOE) complex.

Cognizant managers (CMs)/Designees are responsible for ensuring that Lessons Learned Briefings for these events, issues, or incidents are developed and delivered to target audiences. $\mathrm{CMs} /$ Designees are also responsible for determining the effectiveness and implementation of Lessons Learned within their area(s) of responsibility. Lessons Learned Briefings and materials are maintained in and are available to LBNL personnel via the Lessons Learned/Best Practices Database.

$\mathrm{CMs} /$ Designees are responsible for ensuring that lessons learned and best practices are considered during work planning activities.

Lessons Learned material and sources may include, but are not limited to, the following:

- United States Department of Energy (DOE) Safety Notices

- Nuclear Regulatory Commission (NRC) Bulletins/Notices

- Price Anderson Amendment Act (PAAA) Non-Compliance Tracking System (NTS) Reports

- External Occurrence Reporting and Processing System (ORPS) Reports

- Internal ORPS Summary Reports

- DOE Environmental Safety and Health (ES\&H) Lessons Learned Bulletins 
- Nonconformance Reports (NCRs)

- Corrective Action Requests (CARs)

- Other pertinent industry documents

Records generated during the performance of this procedure are maintained in accordance with the Regulations and Procedures Manual (RPM) and include:

- Lessons Learned/Best Practices documentation, as applicable

Briefing

- Attendance Roster(s)

○ Supporting Material(s)

- Lessons Learned/Best Practices Database

- Lessons Learned/Best Practice Feedback Form

\subsection{REQUIREMENTS}

References

Baseline Documents

- Department of Energy Order (DOE O) 210.2, DOE Corporate Operating Experience Program

- DOE O 226.1, Implementation of Department of Energy Oversight Policy

- DOE O 231.1A, Environmental, Safety and Health Reporting

- DOE O 225.1A, Accident Investigations

- DOE P 450.4, Safety Management System Policy

Referenced Documents

- Regulations and Procedures Manual

- OIA-OCA-0002, Lessons Learned/Best Practices Database User Manual 


\subsection{RESPONSIBILITIES}

$3.1 \quad$ Initiator

3.1.1 Collects and reviews Lessons Learned/Best Practices material that supports Lessons Learned/Best Practices Briefings

3.1.2 Identifies target audiences for Lessons Learned/Best Practices Briefings

3.1.3 Develops Lessons Learned/Best Practices Briefings

3.1.4 May disseminate Lessons Learned/Best Practices Briefings

3.2 OCA

3.2.1 Manages the Lessons Learned/Best Practices Program

3.2.2 May review and approve Lessons Learned/Best Practices Briefings prior to dissemination

\subsection{CM/Designee}

3.3.1 Ensures lessons learned and best practices are considered during work planning activities

3.3.2 Reviews and approves Lessons Learned/Best Practices Briefings prior to dissemination

3.3.3 Provides feedback on applicable Lessons Learned Briefings to determine effectiveness of Lessons Learned Program within area(s) of responsibility

3.3.4 Disseminates Lessons Learned/Best Practices Briefings

3.3.5 Ensures submittal of lessons learned or best practices applicable to other DOE sites to the DOE Corporate Operating Experience Program

\subsection{Additional Reviewer(s)}

3.4.1 Reviews and approves Lessons Learned/Best Practices Briefings prior to dissemination 


\section{Lessons Learned/Best Practice \\ Review Process}

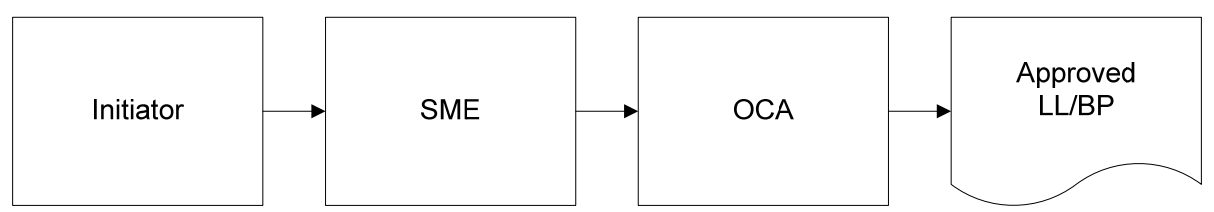

\subsection{LESSONS LEARNED DEVELOPMENT}

Initiator

4.1 Obtain copies of applicable Lessons Learned material, if applicable.

4.2 In conjunction with the Subject Matter Expert (SME), review the Lessons Learned material to determine applicability to LBNL and ensure that it:

4.2.1 Provides significant new information for LBNL, other facilities, sites or programs

4.2.2 Has direct relevance to LBNL

4.2.3 Has the potential to be the basis for significant improvements or cost savings

4.3 Perform research on the incident, event, or issue, as applicable.

\section{NOTE}

Specific software and hardware requirements, user interface, and guidelines on completing database fields are addressed in OIA-OCA-0002, Lessons Learned/Best Practices Database User Manual. This manual is located on the Lessons Learned and Best Practices website.

4.4 Enter the Lessons Learned information, including supporting documentation into the Lessons Learned/Best Practices Database and electronically route the Briefing for review. 


\section{NOTE:}

Once the appropriate reviewers have approved the Lessons Learned Briefing, the Initiator is notified that the LL Briefing has been approved and the Lessons Learned Briefing is electronically disseminated to the target audience. Reviewer is a generic term that may include management, SMEs, OCA, or general employees.

Reviewer(s)

4.5 Upon receipt of the new Lessons Learned Briefing, review to ensure that it is applicable, complete, AND correct.

4.6 Resolve any issues with the Initiator, if applicable.

4.7 Identify additional reviewers, if applicable.

4.8 Electronically approve the Lessons Learned Briefing, by selecting the "Approved" button to electronically disseminate the Lessons Learned Briefing to the appropriate target audience.

4.9 If personnel identified as part of the target audience do not have access to email, ensure that the Lesson Learned Briefing is disseminated (e.g. routing hard copies of briefings or addressing the lesson learned in meetings).

4.10 If the Lessons Learned Briefing is applicable to other DOE sites, ensure submittal of the Briefing to the DOE Corporate Operating Experience Program.

\subsection{BEST PRACTICES DEVELOPMENT}

Initiator

5.1 Obtain Best Practices material, if applicable.

\section{NOTE}

Specific software and hardware requirements, user interface, and guidelines on completing database fields are addressed in OIA-OCA-0002, Lessons Learned/Best Practices Database User Manual. This manual is located on the Lessons Learned and Best Practices website.

5.2 Enter the Best Practices information, including supporting documentation, into the Lessons Learned/Best Practices Database and route the Briefing for review. 


\section{NOTE:}

Once the appropriate reviewers have approved the Best Practices Briefing, the Initiator is notified that the Best Practices Briefing has been approved and it is electronically disseminated to the target audience.

Reviewers

5.3 Upon receipt of the new Best Practices Briefing, review to ensure that it is applicable, complete, AND correct.

5.4 Resolve any issues with the Initiator, if applicable.

5.5 Identify additional reviewers, if applicable.

5.6 Electronically approve the Best Practices Briefing, by selecting the "Approved" button to electronically disseminate the Best Practices Briefing to the appropriate target audience.

5.7 If personnel identified as part of the target audience do not have access to email, ensure that the Best Practices Briefing is disseminated, which may include routing hard copies of briefings or addressing the best practice in meetings.

5.8 If the Best Practices Briefing is applicable to other DOE sites, ensure submittal of the Briefing to the DOE Corporate Operating Experience Program.

\subsection{LESSONS LEARNED AND BEST PRACTICES EFFECTIVENESS}

Target Audience

6.1 Upon receipt of a Lessons Learned/Best Practices Feedback Form, electronically complete the form, and select the "Save" button to route to the appropriate CM, $\mathrm{SME}$, or other designee.

Reviewer(s)

6.2 Periodically review disseminated Lessons Learned/Best Practices Briefings and Feedback Forms.

6.3 Determine the effectiveness and implementation of Lessons Learned/Best Practices program within area of responsibility. 